\title{
Gamma radiation attenuation characteristics of composites based on polyimide track membranes filled with nanodispersed $\mathrm{Pb}$
}

\author{
N.I. Cherkashina ${ }^{\text {a,*, V.I. Pavlenko }}{ }^{\text {a }}$, A.V. Noskov ${ }^{\mathrm{b}}$, N.I. Bondarenko ${ }^{\mathrm{a}}$, O.V. Kuprieva ${ }^{\mathrm{a}}$, N. \\ V. Kashibadze ${ }^{a}$, R.V. Sidelnikov ${ }^{a}$, E.P. Klopot ${ }^{a}$ \\ ${ }^{a}$ Belgorod State Technological University Named After V.G. Shoukhov, Kostyukov str., 46, Belgorod, 308012, Russia \\ ${ }^{\mathrm{b}}$ Belgorod State National Research University, Belgorod, 308015, Pobedy str., 85, Russia
}

\section{A R T I C L E I N F O}

\section{Keywords:}

Polyimide track membranes

Nanodispersed lead

Electrodeposition

$\gamma$-radiation

Linear attenuation coefficient

\begin{abstract}
A B S T R A T
The paper presents data on the effect of $\gamma$-radiation on polymer composites based on polyimide track membranes filled with nanodispersed lead. The radiation-protective properties of the composites were studied by theoretical and experimental methods. To carry out experimental studies on the effect of $\gamma$-radiation on the composite, radioactive sources cesium-137 and cobalt- 60 were used. The calculated data of the linear attenuation coefficient of $\gamma$-radiation in the composite, depending on the initial energy of $\gamma$-quanta in the range from 0.5 to $5 \mathrm{MeV}$, are presented. The contribution of the photoelectric effect, the Compton effect, and the formation of electronpositron pairs to the total linear attenuation coefficient of the gamma radiation of the composite is estimated. When $\gamma$-radiation passes through $2.5 \mathrm{~mm}$ of the composite, the intensity of $\gamma$-radiation absorption decreases by 17.7 and $4.4 \%$ at radiation energies of 0.5 and $5 \mathrm{MeV}$, respectively. It was experimentally established that the introduction of nanodispersed filler $\mathrm{Pb}$ into a polyimide track membrane made it possible to increase the linear attenuation coefficient of $\gamma$-radiation by more than 6 times at an energy of $0.662 \mathrm{MeV}$, and by a factor of 3.7 at an energy of $1.252 \mathrm{MeV}$ as compared to pure polymeric material.
\end{abstract}

\section{Introduction}

Ionizing radiation is widely used in various human activities, including medicine, industry, agriculture, and scientific research. With the development of the use of ionizing radiation, the issue of protecting personnel working at enterprises using radiation technologies arises. One of the most promising methods of protection against radiation exposure is the use of a radiation shield. The selection of the composition of the radiation shield depends on many factors, such as energy, and the duration and type of ionizing radiation. It is known that the best fast neutron moderators are hydrogen-containing materials: polymers, metal hydrides, etc. (Preston and Tickner, 2017; Pavlenko et al., 2015a, 2015b; Abdulrahman et al., 2020; Ibrahima and Mahdib, 2019). It is promising to use cadmium and boron-containing screens from slow (thermal) neutrons (Chrysanthopoulou et al., 2014). To protect against radiation in space, it is promising to use polymer composites, especially based on polyimide (Pavlenko et al., 2014, 2019; Yastrebinsky et al., 2016; Zhang et al., 2021). To protect against X-ray and $\gamma$-radiation, protective screens are used, the filler of which are materials with a high atomic number and high density (W, Bi, $\mathrm{Fe}, \mathrm{Pb}, \mathrm{Ni}$, etc.) (Sverguzova et al., 2019; Mollah, 2018).

The necessary components for protection against a certain type of radiation are added to compositions to create structural elements - walls, partitions, etc. The most widely used are protective screens in the form of concrete structures. Yao et al. found that irradiation of heavy concrete samples with neutrons and gamma rays did not significantly change the mechanical and structural characteristics of the materials (Yao et al., 2016).

Tyagi et al. (2021) showed that for the creation of radiation-shielding concretes it is possible to use industrial waste, including metallurgical waste $\neg$ ferrous and non-ferrous slags. In addition, fly ash, silica and organic synthesis wastes can be used as fillers for radiation-shielding concretes (Tyagi et al., 2021). Akkurt et al. found that an increase in the nuclei of heavy metals in the composition of the filler of radiation-shielding concretes will have a greater effect than an increase in the amount of the added filler (Akkurt et al., 2006).

Gamma-ray shielding based on glass compositions is widely used (Sayyed et al., 2021a; Yasmin et al., 2018; Abouhaswa and Kavaz,

\footnotetext{
* Corresponding author.

E-mail addresses: cherkashina.ni@bstu.ru, natalipv13@mail.ru (N.I. Cherkashina).
} 
2020). Bagheri et al. obtained radiation-protective borate glasses containing barium oxide (II), bismuth oxide (III), lead oxide (II) (Bagheri and Shirmardi, 2021). It was found that the effective atomic cross sections of the glass samples improved by increasing their barium oxide (II), bismuth oxide (III), lead oxide (II) contents. Sayyed et al. found that the addition of $\mathrm{MoO}_{3}$ to borate glasses leads to an increase in the protective properties of glasses in relation to gamma radiation (Sayyed et al., 2021b). For pure borate glass, the linear attenuation coefficient of gamma radiation was 0.557 and $0.218 \mathrm{~cm}^{-1}$ at ionizing radiation energies of 0.184 and $0.81 \mathrm{MeV}$, respectively. With the introduction of 20 $\mathrm{wt} \%$ molybdenum (VI) oxide into borate glass, the linear attenuation coefficient of gamma radiation increased 1.6 and 1.74 times at ionizing radiation energies of 0.184 and $0.81 \mathrm{MeV}$, respectively.

Recently, the direction for the development of radiation-protective screens based on polymers has become topical. They are characterized by a combination of high values of mechanical strength, ease of processing and low cost. The addition of various fillers makes it possible to obtain polymer composites with desired functional properties, including those with high radiation-shielding characteristics. Particular attention has been paid to the technological features of the filler introduction. There are various techniques that allow the filler to be evenly distributed in the polymer matrix. For example, the use of the ultrasonic cavitation method which does not allow highly dispersed filler particles to aggregate (Pavlenko and Cherkashina, 2019). Another promising method is the use of mechano-activation of filler and polymer particles during joint grinding in a mill (Cherkashina et al., 2019; Klyuev et al., 2010; Cherkashina and Pavlenko, 2018; Sirenko et al., 2017). However, the use of the above methods does not completely eliminate particle agglomeration, especially when using nanofillers. Previously, the authors have developed a technique for the synthesis of polymer composites based on polymer track (nuclear) membranes filled with nanofillers in which agglomeration of the filler is completely excluded (Cherkashina et al., 2020). Track (nuclear) membranes are thin polymer films in which there are many through nanoholes (tracks) (Apel, 1995; Ve-iter, 1994; Apel, 2019). By the method of electrochemical deposition, it is possible to fill the tracks of polymer membranes with various metals (Zhu et al., 2015; Gupta and Kumar, 2019; Ferain and Legras, 2003).

The most widespread are track membranes based on polyethylene terephthalate (Kaniukov et al., 2017; Satulu et al., 2019). There are also works on the synthesis of track membranes based on polypropylene, polyvinylidene fluoride, polyethylene naphthalate, polyethylene terephthalate and other polymers (Kakitani et al., 2018; Schauries et al., 2018; He et al., 2006; Starosta et al., 1999). In the previous work of the authors (Cherkashina et al., 2020), the possibility of creating radiation-protective polymer composites based on polyimide track membranes was shown. Polyimide is one of the most radiation-resistant polymeric materials (Wozniak et al., 2016). In addition, it possesses high physical, mechanical, and thermal properties, which significantly ex-

composite, radioactive sources cesium-137 and cobalt- 60 were used.

\section{Materials and research methods}

\subsection{Synthesis of polyimide/lead composites}

Polyimide track (nuclear) membranes manufactured by It4ip (Belgium, https://www.it4ip.be) were used as a polymer matrix for the synthesis of the composites. The pore diameter was $200 \mathrm{~nm}$, the pore density was $5 \times 10^{8} \mathrm{~cm}^{-1}$, and the polyimide membrane was $25 \mu \mathrm{m}$ thick. Electrochemical deposition was used to fill the membrane tracks with nanodispersed lead. For this, a lead cathode coating $210 \mathrm{~nm}$ thick was applied to one side of the polyimide track (nuclear) membrane. Lead coating on the membranes was carried out by the method of dual magnetron sputtering in an UniCoad 200 vacuum installation with an unbalanced magnetic system for $8 \mathrm{~min}$. The electrodeposition of nanodispersed lead into the pores of the track membranes was carried out from an electrolyte solution based on lead tetrafluoroborate $\mathrm{Pb}\left(\mathrm{BF}_{4}\right)_{2}$, at a fixed voltage of $-400 \mathrm{mV}$.

Since the thickness of one polyimide track (nuclear) membrane was $25 \mu \mathrm{m}$, the thickness of the resulting composite was also $25 \mu \mathrm{m}$. To obtain a composite with a greater thickness, the required amount of membranes filled with nanodispersed lead were glued. The membranes were glued using polyamic acid, which, upon hot pressing, turned into polyimide and firmly held the composite layers together. The synthesis of the multilayer structure of the composite is presented in more detail in (Cherkashina et al., 2020).

The samples were examined by scanning electron microscopy using high-tech equipment of the TESCAN MIRA 3 brand.

\subsection{Effects of $\gamma$-radiation on materials}

\subsubsection{Modeling of protective properties}

Modeling of the processes of the passage of $\gamma$-radiation through the materials under study was carried out at an energy of $0.5-5 \mathrm{MeV}$. It was taken into account that the attenuation of $\gamma$-radiation occurs due to the photoelectric effect, the Compton effect, and the effect of the formation of electron-positron pairs. For calculations, we used the well-known formulae describing the cross sections of these processes in a homogeneous material (Leo, 1994):

1) To assess the contribution of the photoelectric effect, we used Equation (1):

$$
\sigma_{f}=4 \pi r_{e}^{2} \alpha^{4} Z^{5} G_{f}(E)
$$

$G_{f}(E)=\frac{(2+\varepsilon)^{3 / 2}}{\varepsilon^{7 / 2}}\left(\frac{4}{3}+(1+\varepsilon) \frac{\varepsilon-1}{\varepsilon+2}\left(1-\frac{1}{2(\varepsilon+1) \sqrt{\varepsilon(2+\varepsilon)}} \ln \left(\frac{1+\varepsilon+\sqrt{\varepsilon(2+\varepsilon)}}{1+\varepsilon-\sqrt{\varepsilon(2+\varepsilon)}}\right)\right)\right)$

pands the field of application of composites based on polyimide (Pan et al., 2020; Liaw et al., 2012). The use of nanosized particles as a filler for track membranes will increase the radiation-protective characteristics of the material as compared to the use of large filler particles (Özdemir et al., 2018; Malekzadeh et al., 2019).

This work presents data on the assessment of the radiation-protective properties of a composite based on polyimide track membranes filled with nanodispersed lead. The radiation-protective properties of the composites were studied by theoretical and experimental methods. To carry out experimental studies on the effect of $\gamma$-radiation on the where $\varepsilon=\mathrm{E} / \mathrm{m}_{\mathrm{e}} \mathrm{c}^{2}, \mathrm{E}$ is the energy of gamma quanta, $\mathrm{m}_{\mathrm{e}} \mathrm{c}^{2}=0.511$ $\mathrm{MeV}$ is the rest energy of an electron, $\mathrm{r}_{\mathrm{e}}=\mathrm{e}^{2} / \mathrm{m}_{\mathrm{e}} \mathrm{c}^{2}=2.810^{-13} \mathrm{~cm}$ is the classical radius of an electron, $\alpha=1 / 137$ - fine structure constant, and $\mathrm{Z}$ is the sequence number of the corresponding element.

2) To estimate the contribution of the Compton scattering process, we used Equation (3):

$\sigma_{K}=2 \pi r_{e}^{2}\left[\frac{1+\varepsilon}{\varepsilon^{2}}\left(\frac{2(1+\varepsilon)}{1+2 \varepsilon}-\frac{\ln (1+2 \varepsilon)}{\varepsilon}\right)+\frac{\ln (1+2 \varepsilon)}{2 \varepsilon}-\frac{1+3 \varepsilon}{(1+2 \varepsilon)^{2}}\right]$ 
3) To estimate the contribution of the process of formation of electronpositron pairs at energies of $\gamma$-quanta in the range of their energies $2 m_{e} c^{2}<E<137 m_{e} c^{2} \mathrm{Z}^{-1 / 3}$, we used Equation (4):

$\sigma_{P}=r_{e}^{2} \alpha Z(Z+1)\left[\frac{28}{9} \ln (2 \varepsilon)-\frac{218}{27}\right]$

The cross-sections are related to attenuation coefficient according to Equation (5):

$\mu_{i}=\sigma_{i} \cdot N_{A} \cdot \sum_{1}^{n} \rho_{j} \frac{Z_{j}^{2}}{A_{i}}$

where $\mu_{i}$ is $\mu_{f}$ or $\mu_{k}$ or $\mu_{p} ; \sigma_{i}$ is $\sigma_{f}$ or $\sigma_{k}$ or $\sigma_{p} ; N_{A}$ - Avogadro's number, equal to $6,02 \cdot 10^{23} ; \rho_{j}$ - the density of the corresponding element, $Z_{j}$ - the sequence number of the corresponding element, $A_{j}$ - the atomic mass of the corresponding element; $\mathrm{n}$ - the number of different atoms in a composite material.

The total attenuation coefficient of $\gamma$-quanta in the materials under study consists of the sum of the attenuation coefficients from each process (Equation (6)):

$\mu=\mu_{f}+\mu_{k}+\mu_{p}$

\subsubsection{Experimental exposure to $\gamma$-radiation}

The determination of the radiation-protective properties of the materials under study was carried out experimentally using two different radioactive sources: cesium-137 and cobalt- 60 . The energy of $\gamma$-quanta of the cesium-137 source was $0.662 \mathrm{MeV}$. The energy of $\gamma$-quanta of the cobalt- 60 source was $1.252 \mathrm{MeV}$. Measurements were made of the intensity of absorption of $\gamma$-radiation without using the test material $\left(I_{0}\right)$, as well as measurements of the intensity of absorption of $\gamma$-radiation using a screen made of the test material with a given thickness $d(I)$. The linear attenuation coefficient of $\gamma$-radiation was calculated based on Equation (7):

$I=I_{0} \cdot e^{-\mu \cdot d}$

The schematic of the experiment is shown in Fig. 1. The detector was used to calculate the equivalent dose rate without the test material, as well as the equivalent dose rate when using a protective screen. Lead blocks $10 \mathrm{~cm}$ thick were used as collimators.

The $\mu_{\mathrm{m}}$ in a composite based on polyimide track membranes was found as the ratio of the linear coefficient of $\gamma$-radiation attenuation $(\mu)$

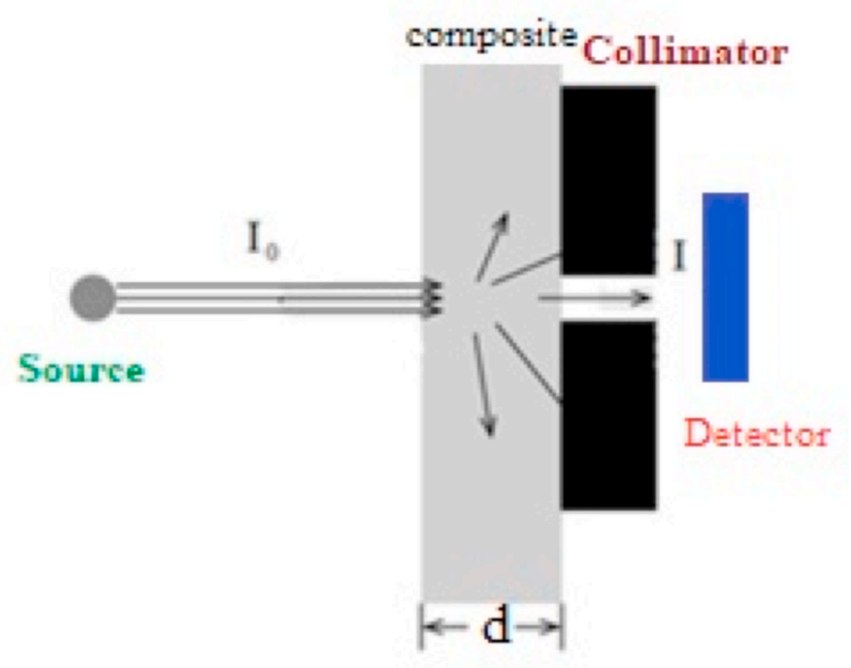

Fig. 1. Scheme of the experiment to determine the radiation-protective properties of the materials under study. to the density of the composite ( $\rho$ ) according to Equation (8):

$\mu_{\mathrm{m}}=\mu / \rho$

MFP, which is defined as the average distance between two successive interactions of photons in an absorber (Bagheri et al., 2017a), was calculated for samples using Equation (9):

$\mathrm{MFP}=1 / \mu$

The absorption of X-ray and $\gamma$-radiation by various substances can be characterized by the value of HVL, i.e., the thickness of the layer, which halves the intensity of the incident rays. The thickness of the halfattenuation layer was found by Equation (10):

$\mathrm{HVL}=0.693 / \mu$

The average value of measurements was determined by Equation (11):

$<x>=\frac{x_{1}+x_{2}+\ldots+x_{n}}{n}=\frac{\sum_{i=1}^{n} x_{i}}{n}$

The variance of the mean value was found by Equation (12):

$S_{<x>}^{2}=\frac{\left(x_{1}-<x>\right)^{2}+\left(x_{2}-<x>\right)^{2}+\ldots+\left(x_{n}-<x>\right)^{2}}{n \cdot(n-1)}$

The standard deviation of the mean value was determined by Equation (13):

$S_{<x>}=\sqrt{S_{<x>}^{2}}$

\section{Results and discussion}

\subsection{Physical and mechanical properties of composites}

Fig. 2 shows an SEM image of the initial polyimide track (nuclear) membrane (a) and the membrane after electrochemical deposition at a fixed voltage of $-400 \mathrm{mV}$ (b). Data analysis Fig. 2a showed that the track exit holes in the form of circles with a diameter of $\approx 200 \mathrm{~nm}$ are clearly visible on the track membrane surface. Track outlets are randomly spaced from each other. One can notice both the presence of single tracks and the overlap of several tracks (Fig. 2a). According to Fig. 2 a, the track concentration was calculated, which is $\approx 5 \times 10^{8} \mathrm{~cm}^{-2}$.

Electrochemical deposition made it possible to completely fill the tracks at the nanoscale level (Fig. 2b). According to the data of energy dispersive analysis, the tracks of the polyimide membrane are filled with metallic lead. To assess the degree of filling of the membrane tracks with nanodispersed lead, the polymer was removed by keeping the composite in a $25 \%$ solution of ammonia water $\mathrm{NH}_{4} \mathrm{OH}$ at room temperature for 2 days. With these parameters of the solution, the polyimide membrane completely dissolves, while nanodispersed lead is inert to this solution. SEM-images of the obtained array of nanowires after chemical dissolution in a $25 \%$ solution of ammonia water $\mathrm{NH}_{4} \mathrm{OH}$ of a polymer membrane are shown in Fig. 3.

Fig. 3 shows that after removal of the polyimide matrix, lead nanowires of regular tubular shape remain. The average nanowire diameter is $180-200 \mathrm{~nm}$. Fig. 3 shows that it is noticeable that the nanowires do not stick together "into bundles", whereas in other works it is described that after removal of the matrix, nanowires can tilt and "stick together" into bundles, which is associated with the effect of surface tension and arises when the wires are "released" from the polymer matrix during its removal (etching) (Frolov et al., 2014). It can also be noted that some nanowires are partially empty (Fig. 3). The incompleteness of the entire volume of the nanoscale with lead is possibly a consequence of the filling of the track with oxygen $\left(\mathrm{O}_{2}\right)$ released during electrochemical deposition.

Based on the data presented in Figs. 2 and 3, it was found that the 


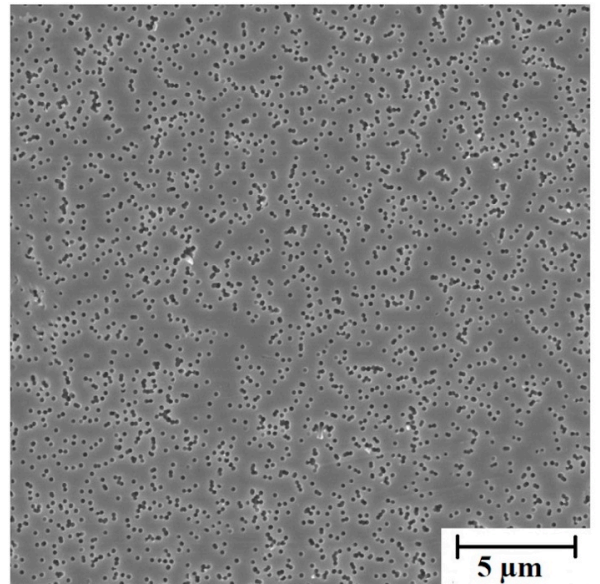

a

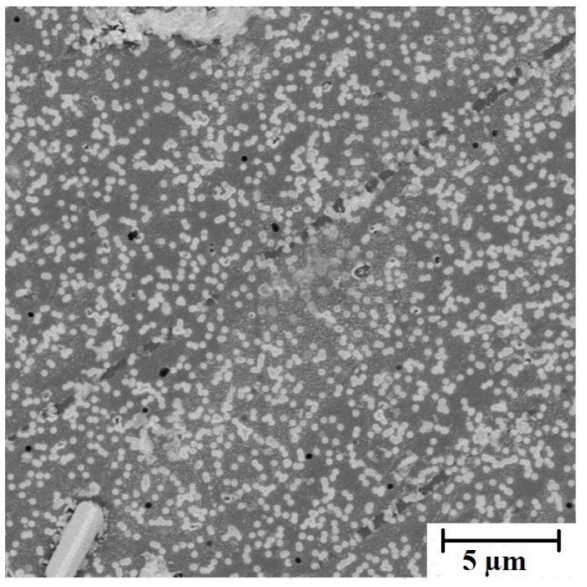

b

Fig. 2. Polyimide track membrane: a) initial, b) after electrochemical deposition.

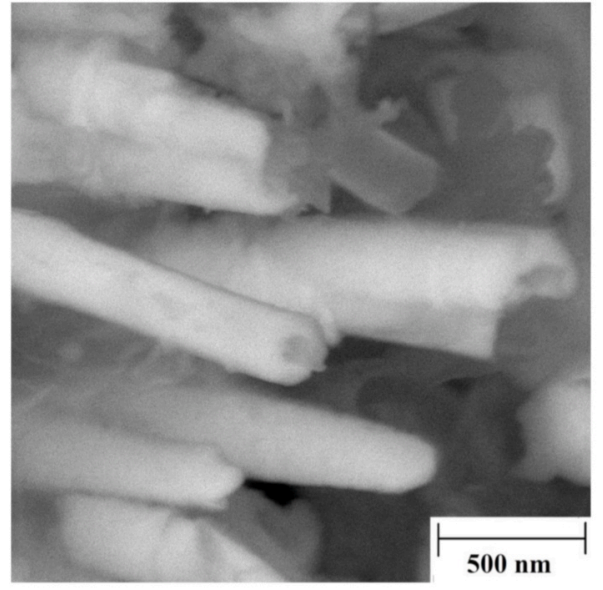

a

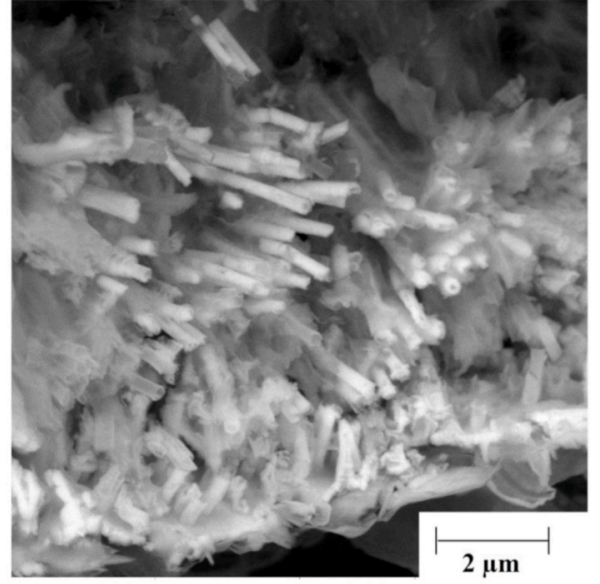

b

Fig. 3. SEM images of replicas of nanodispersed lead in track membrane channels.

proposed method allows filling the track channels of the membrane with nanodispersed lead. Thus, a composite was obtained in which nanodispersed filler made of metallic lead is uniformly distributed, and in which agglomeration of the nanofiller is completely excluded (Fig. 2b). Since the thickness of the obtained composite is due to the thickness of the track membrane - $25 \mu \mathrm{m}$, several layers were glued using polyamic acid to form a composite of greater thickness. Fig. 4 shows a cross section of a multilayer composite formed by hot pressing of 40 layers of polyimide track membranes filled with $\mathrm{Pb}$. Fig. 4 shows that the layers are quite tightly adjacent to each other, thereby forming a single composite without cracks and delamination.

\subsection{Theoretical calculations of the transmission of $\gamma$-radiation through a composite}

For theoretical calculations of the transmission of $\gamma$-radiation through the developed composite based on polyimide track membranes, we used its atomic chemical composition (Table 1).

The density of the developed composite based on polyimide track membranes filled with nanodispersed $\mathrm{Pb}$ was $4.21 \mathrm{~g} / \mathrm{cm}^{3}$. The distance between the lead particles in the tracks was taken as $350 \mathrm{~nm}$ (the average distance between the tracks). The thickness of one polyimide track membrane filled with nanodispersed $\mathrm{Pb}$ is $25 \mu \mathrm{m}$. On one side of the polyimide track membrane, metallic lead $(\mathrm{Pb})$ was sprayed - a lead foil with a thickness of $0.06 \mu \mathrm{m}$. Thus, the total thickness of one track film (one layer) is $25.06 \mu \mathrm{m}$.

Fig. 5 shows the data on the calculated linear attenuation coefficient of $\gamma$-radiation $(\mu)$ in the investigated composite based on polyimide track membranes, depending on the initial energy of $\gamma$-quanta in the range from 0.5 to $5 \mathrm{MeV}$. Fig. 5 also shows the contributions of the photoelectric effect $\left(\mu_{f}\right)$, the Compton effect $\left(\mu_{k}\right)$, and the electron-positron pairing effect $\left(\mu_{p}\right)$ to the total $(\mu)$ linear attenuation coefficient for $\gamma$-radiation. Analysis of the data obtained showed that at a $\gamma$-radiation energy of $0.5-0.75 \mathrm{MeV}$, the photoelectric effect makes the greatest contribution to the $\mu$. At $\gamma$-radiation energies above $0.75 \mathrm{MeV}$, the Compton effect makes the greatest contribution. At a $\gamma$-radiation energy less than $3.37 \mathrm{MeV}$, the contribution of the formation of electronpositron pairs is not observed, and at a $\gamma$-radiation energy higher than $3.37 \mathrm{MeV}$, the contribution of the formation of electron-positron pairs gradually increases and at an energy of more than $4 \mathrm{MeV}$ its contribution becomes much larger in comparison with the Compton effect. At $\gamma$-radiation energies above $4 \mathrm{MeV}$, the contribution of the photoelectric effect and the Compton effect gradually decrease, while the contribution of the formation of electron-positron pairs begins to increases (Fig. 5).

For comparison, Fig. 6 shows the curves of the calculated linear attenuation coefficient of $\gamma$-radiation in the investigated composite based on polyimide track membranes and in a material made of pure lead $(\mathrm{Pb})$, depending on the initial energy of $\gamma$-quanta in the range from 


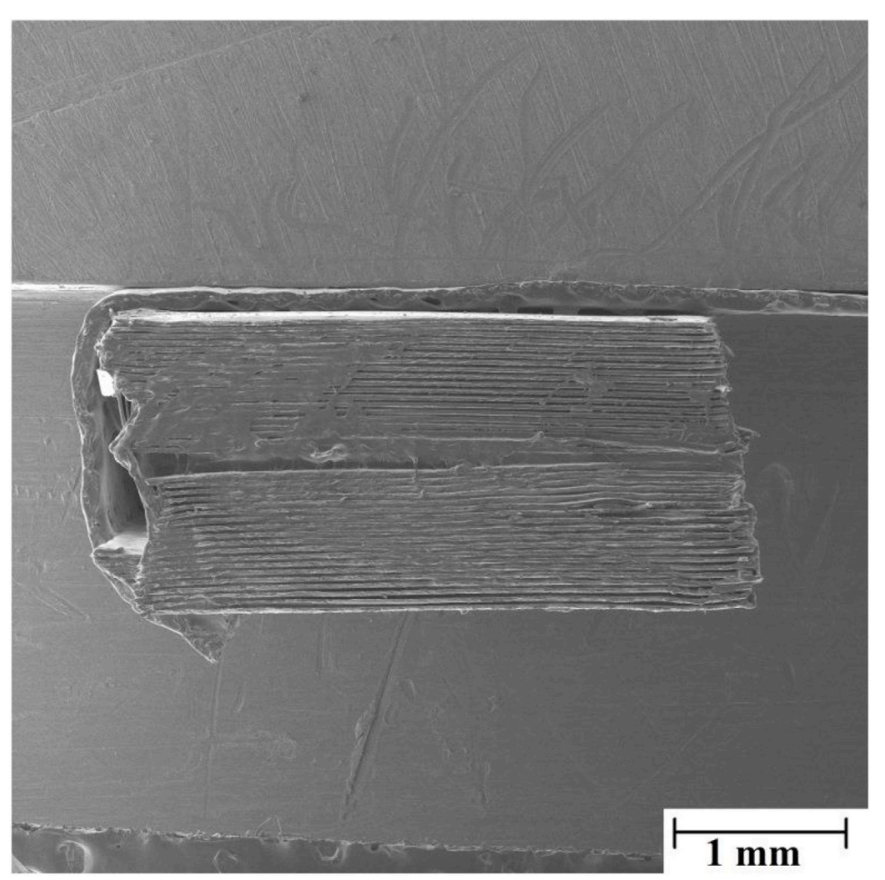

Fig. 4. SEM image of a cross section of a multilayer composite.

Table 1

Atomic chemical composition of the developed composite based on polyimide track membranes.

\begin{tabular}{lllll}
\hline \multicolumn{2}{l}{ Atom content, $\mathrm{wt} \%$} \\
\hline Oxygen & Nitrogen & Hydrogen & Carbon & Lead \\
\hline 5.2 & 1.8 & 0.6 & 16.3 & 76.1 \\
\hline
\end{tabular}

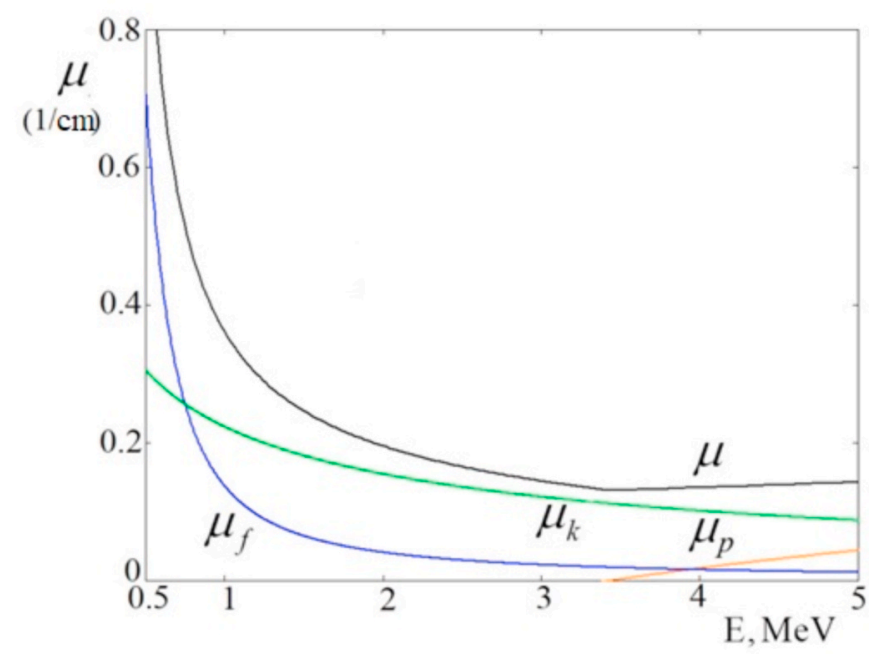

Fig. 5. Calculated $\mu$ in the investigated composite.

0.5 to $5 \mathrm{MeV}$. According to Fig. 6, a material made of pure lead has better radiation-shielding properties in comparison with the investigated polymer composite based on polyimide track membranes. It is noticeable that the curve of the dependence of the linear attenuation coefficient of $\gamma$-radiation $\mathrm{Pb}$ is located above the curve of the considered composite (Fig. 6). However, the density of $\mathrm{Pb}$ is $11.35 \mathrm{~g} / \mathrm{cm}^{3}$, and the density of the developed material is $4.21 \mathrm{~g} / \mathrm{cm}^{3}$. Thus, the density of the polymer composite is 2.7 times less than the density of $\mathrm{Pb}$. In this case,

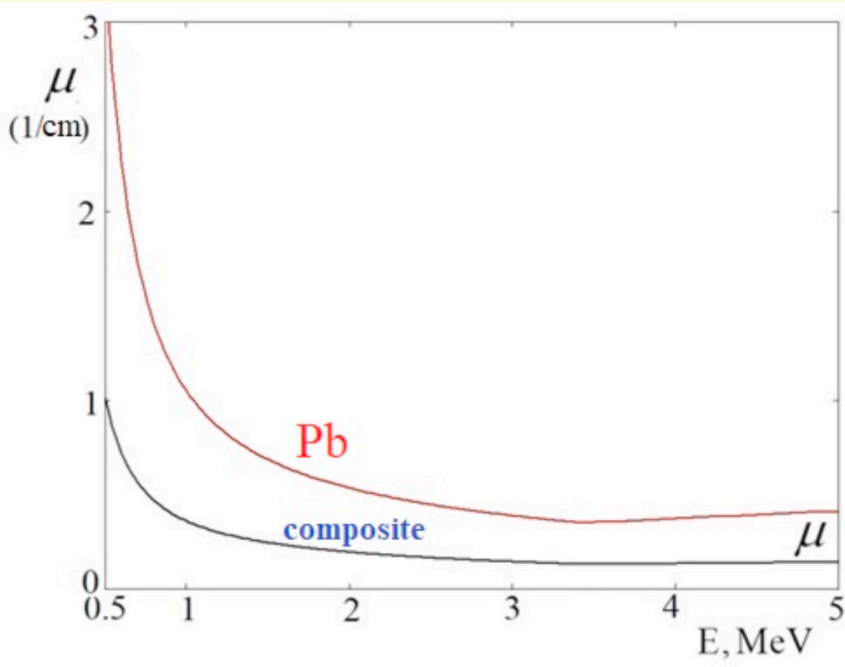

Fig. 6. Curves of the dependence of the linear attenuation coefficient of $\gamma$-radiation for $\mathrm{Pb}$ and a composite based on polyimide track membranes.

sufficiently high values of the linear attenuation coefficient of $\gamma$-radiation of the composite remain (Fig. 6), which is explained by the high lead content of $76.14 \mathrm{wt} \%$ in (Table 1 ).

Fig. 7 shows the curves of the $\gamma$-radiation intensity attenuation in the composite based on polyimide track membranes depending on the number of layers $(\mathrm{N})$. The dependences are presented for two energies $0.5 \mathrm{MeV}$ and $5 \mathrm{MeV}$. From the graphs shown in Fig. 7, it is noticeable that with an increase in the layers, an increase in the absorption of $\gamma$-radiation is observed. In this case, for an energy of $0.5 \mathrm{MeV}$, the attenuation of the intensity of $\gamma$-radiation is much greater than for an energy of $5 \mathrm{MeV}$ with the same number of layers. When $\gamma$-radiation passes through 50 layers, the intensity of $\gamma$-radiation absorption decreases by 8.8 and $2.1 \%$ at radiation energies of 0.5 and $5 \mathrm{MeV}$, respectively. When $\gamma$-radiation passes through 100 layers, a decrease in the intensity of $\gamma$-radiation absorption by 17.7 and $4.4 \%$ occurs at radiation energies of 0.5 and $5 \mathrm{MeV}$, respectively (Fig. 7).

\subsection{Radiation-protective characteristics of the composite}

For the purpose of the investigation five multilayers composites based on polyimide track membranes consisting of $\mathrm{N}=160$ layers were produced. The resulting protective screen was about $4.00 \mathrm{~mm}$ thick. The MKS-01R radiometer-dosimeter recorded the average flux value in a detector $\mathrm{F}(\mathrm{E}, \mathrm{d})$ when using a protective of a fixed thickness, as well as the average flux value in the same detector volume, F (E, 0), in the absence of any shielding material. The measurements were carried out for two shield different radioactive sources ${ }^{137} \mathrm{Cs}$ and ${ }^{60} \mathrm{Co}$. Based on the obtained data and formula (1), the experimental values of the linear attenuation coefficient of $\gamma$-radiation were calculated (Table 2). Table 2 also presents data on the mass attenuation coefficient of $\gamma$-radiation, the mean free path (MFP), and the half-attenuation layer (HVL) of the composite based on polyimide track membranes.

The radiation-protective characteristics of the polymer composite based on polyimide track membranes presented in Table 2 were determined taking into account the confidence interval. The confidence interval was found through the Student's parameter $t$ and the standard deviation of the mean value of the studied parameter.

Analysis of the data in Table 2 showed that with increasing energy, the linear and mass attenuation coefficients of $\gamma$-radiation in the composite based on polyimide track membranes decreased.

To compare the radiation-protective characteristics, Table 3 presents data on the linear and mass attenuation coefficient of the investigated polymer composite based on polyimide track membranes and known 

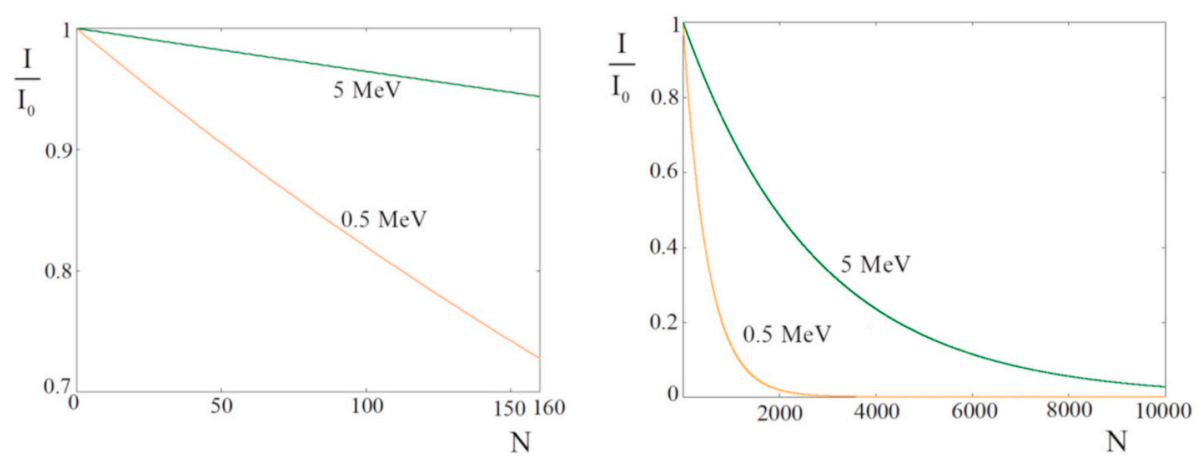

Fig. 7. Attenuation of the intensity of $\gamma$-radiation in a composite based on polyimide track membranes, depending on the number of layers: a) 160 , b) 10,000 .

Table 2

Radiation-protective characteristics of the investigated polymer composites.

\begin{tabular}{llll}
\hline \multirow{2}{*}{ No } & Characteristic & \multicolumn{2}{l}{ Energy of $\gamma$-radiation, MeV } \\
\cline { 3 - 4 } & & 0.662 & 1.252 \\
\hline 1 & $\mu, \mathrm{cm}^{-1}$ & $0.71 \pm 0.07$ & $0.32 \pm 0.02$ \\
2 & $\mu_{\mathrm{m}}, \mathrm{cm}^{2} / \mathrm{g}$ & $0.17 \pm 0.02$ & $0.08 \pm 0.01$ \\
3 & $\mathrm{MFP}, \mathrm{cm}$ & $1.41 \pm 0.14$ & $3.13 \pm 0.19$ \\
4 & $\mathrm{HVL}, \mathrm{cm}$ & $0.97 \pm 0.07$ & $2.16 \pm 0.12$ \\
\hline
\end{tabular}

Table 3

Comparative data of radiation-protective characteristics of the investigated polymer composite based on polyimide track membranes and known radiationprotective materials.

\begin{tabular}{|c|c|c|c|c|c|c|}
\hline \multirow[t]{3}{*}{ No } & \multirow[t]{3}{*}{ Material } & \multirow{3}{*}{$\begin{array}{l}\text { Density, } \\
\left(\mathrm{g} / \mathrm{cm}^{3}\right)\end{array}$} & \multicolumn{4}{|c|}{ Energy, MeV } \\
\hline & & & \multicolumn{2}{|l|}{0.662} & \multicolumn{2}{|l|}{1.252} \\
\hline & & & $\mathrm{cm}^{-1}$ & $\begin{array}{l}\mathrm{m}, \mathrm{cm}^{2} / \\
\mathrm{g}\end{array}$ & $\mathrm{cm}^{-1}$ & $\begin{array}{l}\mathrm{m}, \\
\mathrm{cm}^{2} / \mathrm{g}\end{array}$ \\
\hline 1 & $\begin{array}{l}\text { Composite based } \\
\text { on polyimide track } \\
\text { membranes }\end{array}$ & 4.21 & $\begin{array}{l}0.71 \\
\pm 0.07\end{array}$ & $\begin{array}{l}0.17 \pm \\
0.02\end{array}$ & $\begin{array}{l}0.32 \\
\pm 0.02\end{array}$ & $\begin{array}{l}0.08 \\
\pm 0.01\end{array}$ \\
\hline 2 & $\begin{array}{l}\text { Polyimide ( } \\
\text { Cherkashina et al., } \\
\text { 2021) }\end{array}$ & 1.43 & 0.117 & 0.081 & 0.085 & 0.059 \\
\hline 3 & $\begin{array}{l}\text { Ordinary concrete ( } \\
\text { Bagheri et al., } \\
\text { 2017b) }\end{array}$ & 2.3 & 0.179 & 0.078 & - & - \\
\hline 4 & $\begin{array}{l}\text { Steel-scrap } \\
\text { concrete (Bagheri } \\
\text { et al., 2017b) }\end{array}$ & 4.0 & 0.300 & 0,075 & - & - \\
\hline 5 & $\begin{array}{l}\mathrm{Bi}_{2} \mathrm{O}_{3} \text { glass } 30 \text { wt } \% \\
\text { (Kirdsiri et al., } \\
\text { 2011) }\end{array}$ & 4.887 & 0.39 & 0.08 & - & - \\
\hline 6 & $\begin{array}{l}\text { PbO glass } 40 \text { wt } \% \text { ( } \\
\text { Kirdsiri et al., } \\
2011 \text { ) }\end{array}$ & 4.374 & 0.41 & 0.0947 & & \\
\hline
\end{tabular}

radiation-protective materials. Table 3 presents data for polymeric materials, various types of concrete, and various types of glass.

Analysis of the data presented in Table 3 shows that of all the materials presented, the proposed composite based on polyimide track membranes has the highest values of the linear and mass attenuation coefficients. The introduction of a nanodispersed filler into a polyimide track membrane makes it possible to increase the linear attenuation coefficient of $\gamma$-radiation by more than 6 times at an energy of $E=0.662$ $\mathrm{MeV}$, and by a factor of 3.7 at an energy of $\mathrm{E}=1.252 \mathrm{MeV}$ compared to pure polyimide material (Cherkashina et al., 2021). Compared to the known types of concrete (ordinary and steel-scrap concretes), the composite based on polyimide track membranes has a higher density and a higher $\mu$. At an energy of $\mathrm{E}=0.662 \mathrm{MeV}$, the value of the linear attenuation coefficient of $\gamma$-radiation of the considered composite is almost 4 times higher than that of ordinary concrete, while the density is 1.8 times higher. When comparing the considered polymer composite and $\mathrm{Bi}_{2} \mathrm{O}_{3}$ glass $30 \mathrm{wt} \%$, it can be noted that the density of $\mathrm{Bi}_{2} \mathrm{O}_{3}$ glass is $16 \%$ higher than the composite based on track membranes. However, the linear attenuation coefficient of the composite based on track membranes is $82 \%$ higher than that of $\mathrm{Bi}_{2} \mathrm{O}_{3}$ glass. Most likely, this is due to the content in the composite based on track membranes of a large amount of $\mathrm{Pb}$ particles (76.14 wt\%), on which more $\gamma$-quanta are possibly scattered.

In addition, it can be assumed that the use of the proposed technology for creating a composite, in which the particles of the $\mathrm{Pb}$ nanofiller do not undergo aggregation, also influenced such high values of the radiation-protective characteristics of the composite. To confirm this theory, Table 4 presents the data on the values calculated according to the known formulae and the values obtained experimentally.

Analysis of the data in Table 4 shows that the experimentally obtained values of the linear attenuation coefficient of $\gamma$-radiation of a polymer composite based on polyimide track membranes are $15.6 \%$ and $10.7 \%$ higher than the values obtained theoretically at an energy of $\gamma$-radiation 0.662 and $1.252 \mathrm{MeV}$, respectively. It is known in the literature that the use of nanofillers in comparison with microfillers leads to a significant increase in the radiation-shielding properties of composites. For example, it was shown in (Tekin et al., 2017) that the use of Nano- $\mathrm{WO}_{3}$ leads to an increase in the mass attenuation increase rates from 3.54 to $7.96 \%$ (E from 0.662 to $1.407 \mathrm{MeV}$ ) compared to the use of Micro- $\mathrm{WO}_{3}$.

Sadeghi et al. also studied the effect of micro- and nanoparticle size on gamma-ray mass attenuation values (Sadeghi et al., 2020). The authors studied composites based on silicone rubber with different contents of micro and nanoparticles $\mathrm{WO}_{3}, \mathrm{BaSO}_{4}, \mathrm{PbO}$. The investigated nanoparticles of lead oxide and tungsten oxide had a size not exceeding $200 \mathrm{~nm}$. Studies carried out by Sadeghi et al. have established that nanocomposites have the best radiation-shielding characteristics compared to micro-composites. The work (Li et al., 2017) studied the radiation-protective properties of Epoxy resin matrix composites filled with dispersed micro and nano gadolinium oxide $\left(\mathrm{Gd}_{2} \mathrm{O}_{3}\right)$ particles of different contents. Nano- $\mathrm{Gd}_{2} \mathrm{O}_{3}$ composites have a better ability to

Table 4

Calculated and experimental results on the radiation-protective characteristics of the investigated polymer composite based on polyimide track membranes.

\begin{tabular}{|c|c|c|c|c|c|}
\hline \multirow[t]{3}{*}{ No } & \multirow[t]{3}{*}{ Data type } & \multicolumn{4}{|c|}{ Energy, MeV } \\
\hline & & \multicolumn{2}{|l|}{0.662} & \multicolumn{2}{|l|}{1.252} \\
\hline & & $\begin{array}{l}\text { SYMBOL } \\
109 \backslash \mathrm{f} \\
\text { "Symbol", } \\
\mathrm{cm}^{-1}\end{array}$ & $\begin{array}{l}\text { SYMBOL } 109 \\
\backslash \mathrm{f} \\
\text { "Symbol"m, } \\
\mathrm{cm}^{2} / \mathrm{g}\end{array}$ & $\begin{array}{l}\text { SYMBOL } \\
109 \backslash f \\
\text { "Symbol", } \\
\mathrm{cm}^{-1}\end{array}$ & $\begin{array}{l}\text { SYMBOL } 109 \\
\text { \f } \\
\text { "Symbol"m, } \\
\mathrm{cm}^{2} / \mathrm{g}\end{array}$ \\
\hline 1 & Calculated & 0,614 & & 0,289 & \\
\hline 2 & Experimental & $\begin{array}{l}0.71 \pm \\
0.07\end{array}$ & $0.17 \pm 0.02$ & $\begin{array}{l}0.32 \pm \\
0.02\end{array}$ & $0.08 \pm 0.01$ \\
\hline
\end{tabular}


shield $\mathrm{X}$ and $\gamma$ rays than micro- $\mathrm{Gd}_{2} \mathrm{O}_{3}$ composites, and an enhanced effect of $\sim 28 \%$ is obtained with $\mathrm{Gd}_{2} \mathrm{O}_{3}$ content of around $5 \mathrm{wt} \%$ at 59.5 $\mathrm{keV}$.

\section{Conclusion}

In this study, the linear and mass attenuation coefficients of $\gamma$-radiation of a polymer composite based on polyimide track membranes filled with nanodispersed lead were studied. It has been established by the method of physical and mathematical modeling that at an energy of $\gamma$-radiation from 0.5 to $0.75 \mathrm{MeV}$, the photoelectric effect makes the greatest contribution to the linear attenuation coefficient. At $\gamma$-radiation energies above $0.75 \mathrm{MeV}$, the Compton effect makes the greatest contribution. At a $\gamma$-radiation energy less than $3.37 \mathrm{MeV}$, the contribution of the formation of electron-positron pairs is not observed.

The introduction of a nanodispersed filler into a polyimide track membrane made it possible to increase the linear attenuation coefficient of $\gamma$-radiation by more than 6 times at an energy of $\mathrm{E}=0.662 \mathrm{MeV}$, and by a factor of 3.7 at an energy of $\mathrm{E}=1.252 \mathrm{MeV}$ as compared to a pure polyimide material.

The experimentally obtained values $\mu$ of the polymer composite based on polyimide track membranes are $15.6 \%$ and $10.7 \%$ higher than the values obtained theoretically at the $\gamma$-radiation energy 0.662 and $1.252 \mathrm{MeV}$, respectively. The high values of the radiation-protective properties of the composite are due to the proposed technology for creating the composite, in which the particles of the $\mathrm{Pb}$ nanofiller do not undergo aggregation.

The obtained multilayer composites based on polyimide track membranes and nanodispersed lead can find application in the medical and nuclear industries. On their basis, it is possible to manufacture flexible radiation-protective screens and vests to protect personnel from $\mathrm{X}$-ray and gamma radiation.

\section{Declaration of competing interest}

The authors declare that they have no known competing financial interests or personal relationships that could have appeared to influence the work reported in this paper.

\section{Acknowledgment}

The work was supported by a project of the Russian Science Foundation (№19-79-10064).

\section{References}

Abdulrahman, S.T., Ahmad, Z., Thomas, S., Rahman, A.A., Abdulrahman, S.T., Thomas, S., Ahmad, Z., 2020. Chapter 1 - introduction to neutron-shielding materials. In: In Woodhead Publishing Series in Composites Science and Engineering, Micro and Nanostructured Composite Materials for Neutron Shielding Applications. Woodhead Publishing, pp. 1-23. https://doi.org/10.1016/B978-0-12819459-1.00001-5.

Abouhaswa, A.S., Kavaz, E., 2020. A novel $\mathrm{B}_{2} \mathrm{O}_{3}-\mathrm{Na}_{2} \mathrm{O}-\mathrm{BaO}-\mathrm{HgO}$ glass system: synthesis, physical, optical and nuclear shielding features. Ceram. Int. 46, 16166-16177. https://doi.org/10.1016/j.ceramint.2020.03.172.

Akkurt, I., Basyigit, C., Kilincarslan, S., Mavi, B., Akkurt, A., 2006. Radiation shielding of concretes containing different aggregates. Cement Concr. Compos. 28 (2), 153-157. https://doi.org/10.1016/j.cemconcomp.2005.09.006.

Apel, P.Yu, 1995. Heavy particle tracks in polymers and polymeric track membranes. Radiat. Meas. 25 (1-4), 667-674. https://doi.org/10.1016/1350-4487(95)00219-5.

Apel, P.Yu, 2019. Fabrication of functional micro- and nanoporous materials from polymers modified by swift heavy ions. Radiat. Phys. Chem. 159, 25-34. https://doi. org/10.1016/j.radphyschem.2019.01.009.

Bagheri, R., Shirmardi, S.P., 2021. Gamma-ray shielding studies on borate glasses containing $\mathrm{BaO}, \mathrm{Bi}_{2} \mathrm{O}_{3}$, and $\mathrm{PbO}$ in different concentrations. Radiat. Phys. Chem. 184, 109434. https://doi.org/10.1016/j.radphyschem.2021.109434.

Bagheri, R., Moghaddam, A.K., Yousefnia, H., 2017a. Gamma ray shielding study of barium-bismuth-borosilicate glasses as transparent shielding materials using MCNP4C code, XCOM program, and available experimental data. Nucl. Eng. Technol. 49 (1), 216-223. https://doi.org/10.1016/j.net.2016.08.013.
Bagheri, R., Moghaddam, A.K., Yousefi, A., 2017b. Gamma-ray shielding study of light to heavyweight concretes using MCNP-4C code. Nucl. Sci. Tech. 28, 15. https://doi. org/10.1007/s41365-016-0167-6.

Cherkashina, N.I., Pavlenko, A.V., 2018. Synthesis of polymer composite based on polyimide and $\mathrm{Bi}_{12} \mathrm{SiO}_{20}$ sillenite. Polym. Plast. Technol. Eng. 57 (18), 1923-1931. https://doi.org/10.1080/03602559.2018.1447129.

Cherkashina, N.I., Pavlenko, V.I., Noskov, A.V., 2019. Synthesis and property evaluations of highly filled polyimide composites under thermal cycling conditions from $-190{ }^{\circ} \mathrm{C}$ to $+200{ }^{\circ} \mathrm{C}$. Cryogenics 104,102995 . https://doi.org/10.1016/j. cryogenics.2019.102995.

Cherkashina, N.I., Pavlenko, V.I., Manaev, V.A., Kuprieva, O.V., Kashibadze, N.V., Samoilova, E.S., 2020. Multilayer coatings based on polyimide track membranes and nanodispersed lead. Prog. Org. Coating 138, 105432. https://doi.org/10.1016/j. porgcoat.2019.105432.

Cherkashina, N.I., Pavlenko, V.I., Noskov, A.V., Sirota, V.V., Zaitsev, S.V., Prokhorenkov, D.S., Sidelnikov, R.V., 2021. Gamma radiation attenuation characteristics of polyimide composite with $\mathrm{WO}_{2}$. Prog. Nucl. Energy 137, 103795. https://doi.org/10.1016/j.pnucene.2021.103795.

Chrysanthopoulou, N., Savva, P., Varvayanni, M., Catsaros, N., 2014. Compilation of existing neutron screen technology. Sci. Technol. Nucl. Install. 2014, 23. https://doi. org/10.1155/2014/395795. Article ID 395795.

Ferain, E., Legras, R., 2003. Track-etch templates designed for micro- and nanofabrication. Nucl. Instrum. Methods Phys. Res. B 208, 115-122. https://doi. org/10.1016/S0168-583X(03)00637-2.

Frolov, K.V., Zagorskii, D.L., Lyubutin, I.S., Korotkov, V.V., Bedin, S.A., Sulyanov, S.N., Artemov, V.V., Mchedlishvili, B.V., 2014. Synthesis, phase composition, and magnetic properties of iron nanowires prepared in the pores of polymer track-etched membranes. JETP Lett. (Engl. Transl.) 99, 570-576. https://doi.org/10.1134/ S0021364014100051.

Gupta, R., Kumar, R., 2019. Influence of low energy ion beam implantation on $\mathrm{Cu}$ nanowires synthesized using scaffold-based electrodeposition. Nano-Struct. NanoObjects 18, 100318. https://doi.org/10.1016/j.nanoso.2019.100318.

He, X., Sun, Z., Wan, C., 2006. Track polypropylene membrane based on irradiation with fragments from fission of uranium. Radiat. Meas. 41 (1), 112-113. https://doi.org/ 10.1016/j.radmeas.2005.04.003.

Ibrahima, M.A., Mahdib, K.H., 2019. Design and manufacture of neutrons shield from composite materials. AIP Conf. Proc. 2190, 020047 https://doi.org/10.1063/ 1.5138533.

Kakitani, K., Koshikawa, H., Yamaki, T., Yamamoto, S., Sato, Y., Sugimoto, M., Sawada, S., 2018. Preparation of conductive layer on polyimide ion-track membrane by Ar ion implantation. Surf. Coating. Technol. 355, 181-185. https://doi.org/ 10.1016/j.surfcoat.2018.05.057.

Kaniukov, E.Y., Shumskaya, E.E., Yakimchuk, D.V., Kozlovskiy, A.L., Ibragimova, M.A., Zdorovets, M.V., 2017. Evolution of the polyethylene terephthalate track membranes parameters at the etching process. J. Contemp. Phys. 52, 155-160. https://doi.org/ 10.3103/S1068337217020098.

Kirdsiri, K., Kaewkhao, J., Chanthima, N., Limsuwan, P., 2011. Comparative study of silicate glasses containing $\mathrm{Bi}_{2} \mathrm{O}_{3}, \mathrm{PbO}$ and $\mathrm{BaO}$ : radiation shielding and optical properties. Ann. Nucl. Energy 38, 1438-1441. https://doi.org/10.1016/j. anucene.2011.01.031.

Klyuev, V.A., Loznetsova, N.N., Malkin, A.I., Toporov, YuP., 2010. Effect of the mechanical activation of fillers on the parameters of thermostimulated current in polymer composites. Tech. Phys. Lett. 36 (8), 739-740. https://doi.org/10.1134/ S1063785010080183.

Leo, W.R., 1994. Passage of radiation through matter. In: Techniques for Nuclear and Particle Physics Experiments. Springer, Berlin, Heidelberg. https://doi.org/10.1007/ 978-3-642-57920-2_2.

Li, R., Gu, Y., Wang, Y., Yang, Z., Li, M., Zhang, Z., 2017. Effect of particle size on gamma radiation shielding property of gadolinium oxide dispersed epoxy resin matrix composite. Mater. Res. Express 4, 035035. https://doi.org/10.1088/2053-1591/ aa6651.

Liaw, D.-J., Wang, K.-L., Huang, Y.-C., Lee, K.-R., Lai, J.-Y., Ha, C.-S., 2012. Advanced polyimide materials: syntheses, physical properties and applications. Prog. Polym. Sci. 37 (7), 907-974. https://doi.org/10.1016/j.progpolymsci.2012.02.005.

Malekzadeh, R., Mehnati, P., Sooteh, M.Y., Mesbahi, A., 2019. Influence of the size of nano- and microparticles and photon energy on mass attenuation coefficients of bismuth-silicon shields in diagnostic radiology. Radiol. Phys. Technol. 12 (3), 325-334. https://doi.org/10.1007/s12194-019-00529-3.

Mollah, A.S., 2018. Evaluation of gamma radiation attenuation characteristics of different type shielding materials used in nuclear medicine services. Bangladesh J. Nucl. Med. 21 (2), 108-114. https://doi.org/10.3329/bjnm.v21i2.40361.

Özdemir, T., Güngör, A., Akbay, I.K., Uzun, H., Babucçuoglu, Y., 2018. Nano lead oxide and epdm composite for development of polymer based radiation shielding material: gamma irradiation and attenuation tests. Radiat. Phys. Chem. 144, 248-255. https://doi.org/10.1016/j.radphyschem.2017.08.021.

Pan, Z., Han, S., Wang, J., Qi, S., Tian, G., Wu, D., 2020. Polyimide fabric-reinforced polyimide matrix composites with excellent thermal, mechanical, and dielectric properties. High Perform. Polym. 32 (10), 1085-1093. https://doi.org/10.1177/ 0954008320928387.

Pavlenko, V.I., Cherkashina, N.I., 2019. Effect of $\mathrm{SiO}_{2}$ crystal structure on the stability of polymer composites exposed to vacuum ultraviolet radiation. Acta Astronaut. 155, 1-9. https://doi.org/10.1016/j.actaastro.2018.11.017.

Pavlenko, V.I., Edamenko, O.D., Cherkashina, N.I., Noskov, A.V., 2014. Total energy losses of relativistic electrons passing through a polymer composite. J. Synch. Investig. 8, 398-403. https://doi.org/10.1134/S1027451014020402. 
Pavlenko, V.I., Kuprieva, O.V., Cherkashina, N.I., Yastrebinskii, R.N., 2015a. Defects in modified titanium hydride crystals subjected to heat treatment. Russ. Phys. J. 58, 724-729. https://doi.org/10.1007/s11182-015-0557-y.

Pavlenko, V.I., Edamenko, O.D., Cherkashina, N.I., Kuprieva, O.V., Noskov, A.V., 2015b. Study of the attenuation coefficients of photon and neutron beams passing through titanium hydride. J. Surf. Invest. 9, 546-549. https://doi.org/10.1134/ S1027451015030337.

Pavlenko, V.I., Cherkashina, N.I., Zaitsev, S.V., 2019. Fabrication and characterization of nanocomposite films $\mathrm{Al}, \mathrm{Cu} / \mathrm{Al}$ and $\mathrm{Cr} / \mathrm{Al}$ formed on polyimide substrate. Acta Astronaut. 160, 489-498. https://doi.org/10.1016/j.actaastro.2019.02.025.

Preston, R.M., Tickner, J.R., 2017. Fast-neutron survey with compact plastic scintillation detectors. Radiat. Protect. Dosim. 175 (3), 406-412. https://doi.org/10.1093/rpd/ ncw364.

Sadeghi, Z.V., Jahanbakhsh, O., Okutan, M., Mesbahi, A., 2020. The preparation and characterization of silicon-based composites doped with $\mathrm{BaSO}_{4}, \mathrm{WO}_{3}$, and $\mathrm{PbO}$ nanoparticles for shielding applications in positron emission tomography (PET) and nuclear medicine facilities. Nanomed J 7 (4), 324-334. https://doi.org/10.22038/ nmj.2020.07.00009.

Satulu, V., Mitu, B., Pandele, A.M., Voicu, S.I., Kravets, L., Dinescu, G., 2019. Composite polyethylene terephthalate track membranes with thin teflon-like layers: preparation and surface properties. Appl. Surf. Sci. 476, 452-459. https://doi.org/10.1016/j apsusc.2019.01.109.

Sayyed, M.I., Almuqrin, A.H., Kurtulus, R., Hila, A.M.V.J., Kaky, K., Kavas, T., 2021a. $\mathrm{X}$ ray shielding characteristics of $\mathrm{P}_{2} \mathrm{O}_{5}-\mathrm{Nb}_{2} \mathrm{O}_{5}$ glass doped with $\mathrm{Bi}_{2} \mathrm{O}_{3}$ by using EPICS2017 and Phy X/PS. Appl. Phys. A 127, 243. https://doi.org/10.1007/s00339021-04405-z.

Sayyed, M.I., Mahmoud, K.A., Lacomme, E., AlShammari, M.M., Dwaikat, N., Alajerami, Y.S.M., Alqahtani, M., El-bashir, B.O., Mhareb, M.H.A., 2021b. Development of a novel $\mathrm{MoO}_{3}$-doped borate glass network for gamma-ray shielding applications. Eur. Phys. J. Plus 136, 108. https://doi.org/10.1140/epjp/s13360-02001011-5, 2021.

Schauries, D., Mota-Santiago, P., Gilbert, E.P., Kirby, N., Trautmann, C., Kluth, P., 2018 Structure, morphology and annealing behavior of ion tracks in polycarbonate. Eur. Polym. J. 108, 406-411. https://doi.org/10.1016/j.eurpolymj.2018.09.025.

Sirenko, H., Soltys, L., Sulyma, I., Martynyuk, M., 2017. Methods of thermochemical and mechanical activation of fillers of polymer composite materials. Phys. Chem. Solid State. 18 (2), 249-251. https://doi.org/10.15330/pcss.18.2.249-251.
Starosta, W., Wawszczak, D., Sartowska, B., Buczkowski, M., 1999. Investigations of heavy ion tracks in polyethylene naphthalate films. Radiat. Meas. 31 (1-6), 149-152. https://doi.org/10.1016/S1350-4487(99)00184-5.

Sverguzova, S.V., Khunadi, L., Voronina, YuS., 2019. Heavy metals in the environment and their transformation. Chem. Bull. 2 (2), 9-14.

Tekin, H.O., Singh, V.P., Manici, T., 2017. Effects of micro-sized and nano-sized $\mathrm{WO}_{3}$ on mass attenauation coefficients of concrete by using MCNPX code. Appl. Radiat. Isot. 121, 122-125. https://doi.org/10.1016/j.apradiso.2016.12.040.

Tyagi, G., Singhal, A., Routroy, S., Bhunia, D., Lahoti, M., 2021. Radiation Shielding Concrete with alternate constituents: an approach to address multiple hazards. J. Hazard Mater. 404 (B), 124201. https://doi.org/10.1016/j.jhazmat.2020.124201.

Ve-iter, J., 1994. SEM investigations of etched heavy ion tracks. Scanning 16, 118-122.

Wozniak, A.I., Ivanov, V.S., Kosova, O.V., Yegorov, A.S., 2016. Thermal properties of polyimide composites with nanostructured silicon carbide. Orient. J. Chem. 32 (6) https://doi.org/10.13005/ojc/320616.

Yao, Y., Zhang, X., Li, M., Yang, R., Jiang, T., Lv, J., 2016. Investigation of gamma ray shielding efficiency and mechanical performances of concrete shields containing bismuth oxide as an environmentally friendly additive. Radiat. Phys. Chem. 127, 188-193. https://doi.org/10.1016/j.radphyschem.2016.06.028.

Yasmin, S., Barua, B.S., Khandaker, M.U., Rashid, M.A., Bradley, D.A., Olatunji, M.A., Kamal, M., 2018. Studies of ionizing radiation shielding effectiveness of silica-based commercial glasses used in Bangladeshi dwellings. Results Phys. 9, 541-549. https://doi.org/10.1016/j.rinp.2018.02.075.

Yastrebinsky, R.N., Pavlenko, Z.V., Yastrebinskaya, A.V., Denisova, L.V., 2016. Heatresistant polymeric composite materials based on nano-filled polyalkanimides. Bull. Belgorod State Technol. Univ, named after V.G. Shukhov. 9, 183-188.

Zhang, Y., Wu, H., Guo, Y., Yang, Y., Yu, Q., Liu, J., Wu, B., Lv, F., 2021. Atomic oxygenresistant polyimide composite films containing nanocaged polyhedral oligomeric silsesquioxane components in matrix and fillers. Nanomaterials 11, 141. https://doi. org/10.3390/nano11010141.

Zhu, X.R., Wang, C.M., Fu, Q.B., Jiao, Z., Wang, W.D., Qin, G.Y., Xue, J.M., 2015 Preparation of Ag/Cu Janus nanowires: electrodeposition in track-etched polymer templates. Nucl. Instrum. Methods Phys. Res. B: Beam Interact. Mater. Atoms 356-357, 57-61. https://doi.org/10.1016/j.nimb.2015.04.061. 